\section{An Orbital Shaker}

\author{
K. W. KEOHANE AND W. K. METCALF \\ From the Department of Anatomy, the University, \\ Bristol
}

\section{(RECEIVED FOR PUBLICATION MAY 16, 1959)}

Conventional shaking devices of the reciprocating pattern are frequently noisy, mechanically complex, and may consume considerable power for the work they are required to do. Various attempts to reduce some or all of these disadvantages have resulted in machines such as the suspended shaker devised by Kantovitch ; but this, like most if not all others, is of a reciprocating pattern.

A laboratory shaker, which could be left running continuously and reliably for long periods in a room where others were working, was required, and an orbital shaker has been developed (Fig. 1) which does not possess the disadvantages of reciprocating shakers. The prototype is suitable for the continuous shaking of 16 flasks of $250 \mathrm{ml}$. capacity each containing about $150 \mathrm{ml}$. of fluid.

The shaking unit consists of a number of tiers (in the prototype, two, but there is no reason why more should not be used), on which the flasks are arranged in a regular pattern. Through the centres of the platforms constituting the tiers passes a shaft running in ball bearings top and bottom. Two arms carry out - of - balance weights, adjustable in position and mass, at each end of the shaft. When the shaft is rotated an orbital shaking motion is transmitted to the unit which is suspended in an angle iron frame by wire or nylon cords. The amplitude of the shake is determined by the position and size of

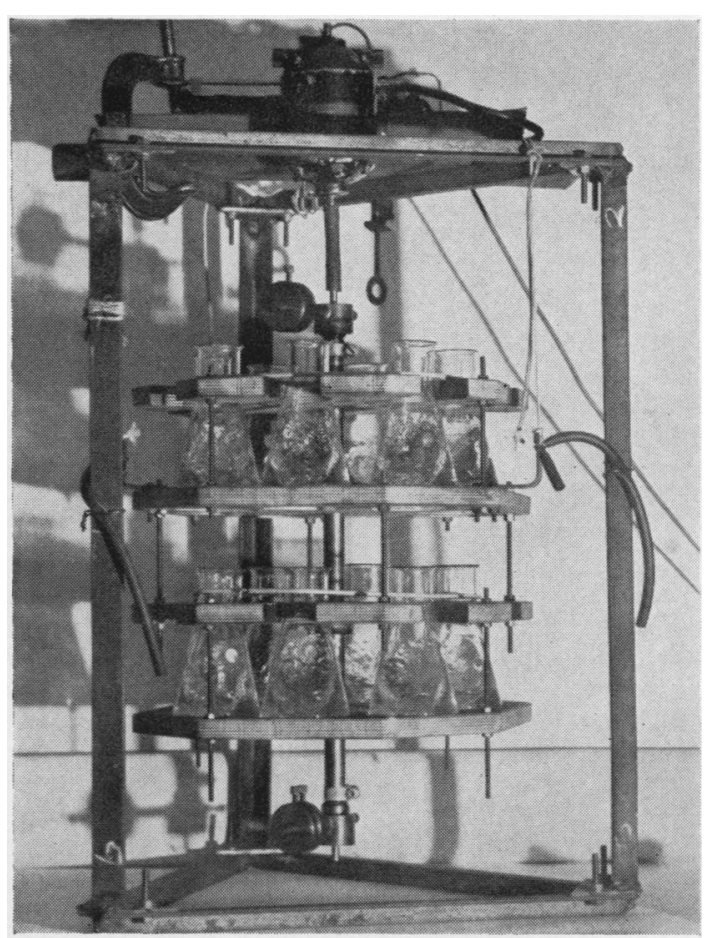

Fig. 1

the weights, whilst the frequency of the shake is determined by the shaft speed. The shaft is connected by a flexible coupling to a fractional horse-power motor fitted with a speed control. To obtain complete stability, the motion was damped by suitable lengths of flexible tubing connecting the frame to the shaking unit.

The shaker has been left running unattended for long periods and is exceptionally quiet in operation. 